\title{
Vaccination and Immunity toward Measles: A Serosurvey in Future Healthcare Workers
}

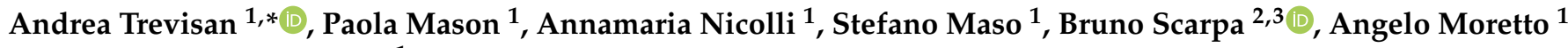 \\ and Maria Luisa Scapellato ${ }^{1}$
}

1 Department of Cardiac Thoracic Vascular Sciences and Public Health, University of Padova, 35128 Padova, Italy; paola.mason.1@unipd.it (P.M.); annamaria.nicolli@unipd.it (A.N.); stefano.maso@unipd.it (S.M.); angelo.moretto@unipd.it (A.M.); marialuisa.scapellato@unipd.it (M.L.S.)

2 Department of Statistical Sciences, University of Padova, 35128 Padova, Italy; bruno.scarpa@unipd.it

3 Department of Mathematics "Tullio Levi-Civita", University of Padova, 35128 Padova, Italy

* Correspondence: andrea.trevisan@unipd.it

Citation: Trevisan, A.; Mason, P.; Nicolli, A.; Maso, S.; Scarpa, B.; Moretto, A.; Scapellato, M.L. Vaccination and Immunity toward Measles: A Serosurvey in Future Healthcare Workers. Vaccines 2021, 9, 377. https://doi.org/10.3390/ vaccines 9040377

Academic Editor: Steven B. Bradfute

Received: 18 March 2021

Accepted: 10 April 2021

Published: 13 April 2021

Publisher's Note: MDPI stays neutral with regard to jurisdictional claims in published maps and institutional affiliations.

Copyright: (c) 2021 by the authors. Licensee MDPI, Basel, Switzerland. This article is an open access article distributed under the terms and conditions of the Creative Commons Attribution (CC BY) license (https:/ / creativecommons.org/licenses/by/ $4.0 /)$.

\begin{abstract}
Measles is a very contagious infectious disease, and vaccination is the only medical aid to counter the spread of the infection. The aim of this study was to evaluate the influence of vaccination schedule and type of vaccine, number of doses, and sex on the immune response. In a population of Italian medical students (8497 individuals born after 1980 with certificate of vaccination and quantitative measurement of antibodies against measles), the prevalence of positive antibodies to measles and antibody titer was measured. Vaccination schedule such as number of doses and vaccine type (measles alone or combined as measles, mumps and rubella (MMR)) and sex were the variables considered to influence the immune response. The vaccination schedule depends on the year of birth: students born before 1990 were prevalently vaccinated once and with measles vaccine alone (not as MMR). One dose of vaccine induces a significantly $(p<0.0001)$ higher positive response and antibody titer than two doses, in particular when measles alone is used $(p<0.0001)$. Females have a significantly higher percentage of positive response $(p=0.0001)$ than males but only when the MMR formulation was used. Multiple linear regression confirms that sex significantly influences antibody titer when only MMR is used, after one $(p=0.0002)$ or two $(p=0.0060)$ doses. In conclusion, vaccination schedule and, partially, sex influence immune response to measles vaccination. Most notably, the measles vaccine alone (one dose) is more effective than one and two doses of MMR.
\end{abstract}

Keywords: measles; vaccination schedule; vaccination response; students; healthcare workers

\section{Introduction}

The vaccination toward measles (one dose schedule) was introduced in Italy in 1976 and implemented since 1979 [1]; the combined measles, mumps, and rubella (MMR, rather two doses) vaccine was introduced in 1999 [2] and approved by the National Plan for eradication of measles and congenital rubella [3], according to the objectives of World Health Organization 2012-2020 [4]. Since 7 June 2017 MMR is mandatory in Italy [5] for newborns and adolescents until 16 years of age. In addition, the Italian National Vaccination Prevention Plan (NVPP) 2017-2019 [6] strongly suggests that healthcare workers (HCWs) be vaccinated toward seven transmittable diseases among which MMR. On the same track, the Italian Multidisciplinary Society for Infection Prevention in Health Organizations, the Italian Society of Occupational Health, the Italian Society of Hygiene, and others have drawn up the so-called "Pisa card" [7] signed during the Pisa conference on 27-28 March 2017 related to the vaccination of HCWs (currently excluded by mandatory vaccination).

Vaccinations for HCWs are an important issue, and in the face of hesitancy phenomena, there is discussion on the need for at least those indicated by the NVPP and the Pisa card to be made mandatory. In these days, in the middle of the COVID-19 pandemic, there is discussion about the need for the vaccine to be mandatory for HCWs. 
The current vaccination schedule for MMR provides a first dose in the second year of life and, according to elimination plane [3], a second dose at 5-6 (recommended) or 11-12 years of age. The vaccination coverage for MMR reached in Italy a peak in 2010 $(90.6 \%)$, falling short to the critical rate for measles to reach the herd immunity greater than $95 \%$ [8].

It has been recognized that the effectiveness of the first dose of measles vaccine is more than $95 \%$, increasing to more than $99 \%$ after the second dose; the immunity persists for a long time [9]. A recent study reports that 15 years after the second dose of MMR vaccine, the rate of measles seropositivity was around $95 \%$. According to this, the two-dose schedule is strongly recommended [10].

Our previous research [11-14] provided evidence that medical school students were not completely protected, at least as regards the rate of circulating antibodies.

The aim of this study was to thoroughly analyze the history of measles vaccination (age at vaccination, number of doses, vaccination schedule, time since the last dose) to evaluate vaccination coverage and immunization toward measles in a cohort of students belonging to the Medical School of Padua University (Padua, Italy).

\section{Materials and Methods}

\subsection{Population}

According to Italian law on safety and health at work [15], the students belonging to the degree courses of the Medical School of Padua University (medicine and surgery, dentistry, and healthcare professions) are submitted to health surveillance in the second (medicine and surgery until 2016 and dentistry) or the first (medicine and surgery since 2017 and healthcare professions) year of course. From 2004 until February 2020, 13,553 students had been screened measuring antibodies of transmissible, but preventable diseases. Enrollment criteria included (i) having been vaccinated against measles, (ii) having been born in Italy, and hence having likely the same vaccination schedules since 1980, as measles vaccination was implemented in Italy in 1979, (iii) availability of the certificate of vaccination released from the Public Health Office, and (iv) a quantitative measurement of antibodies against measles. According to these criteria (Figure 1), enrolled students were 8497 (62.7\%) (2990 males and 5507 females, ratio males/females 0.54). Unvaccinated students (531, 5.9\%) were excluded.

As it is specified in Table 1, the group of vaccinated subjects toward measles had a mean age of $21.1 \pm 2.0$ years without significant differences between males and females, and the geographical origins were prevalently from Northern Italy and Veneto Region.

\subsection{Vaccination Schedule}

Depending on the year of birth, the measles vaccination schedule was different. The vaccination certificates released by the Public Health Office demonstrate that measles vaccine was administered with one dose, measles alone or MMR, or with two doses (two doses of measles alone, a dose of measles alone plus one dose of MMR or two doses of MMR).

Table 1. Characteristics of enrolled students according to graduate course and geographical origin.

\begin{tabular}{ccccccccccc}
\hline Students & $\boldsymbol{N}$. & $\begin{array}{c}\text { Age at } \\
\text { Analysis }\end{array}$ & $\begin{array}{c}\text { Medicine } \\
\text { and Surgery }\end{array}$ & Dentistry & $\begin{array}{c}\text { Healthcare } \\
\text { Professions }\end{array}$ & $\begin{array}{c}\text { Northern } \\
\text { Italy }\end{array}$ & $\begin{array}{c}\text { Central } \\
\text { Italy }\end{array}$ & $\begin{array}{c}\text { Southern } \\
\text { Italy }\end{array}$ & Veneto & Padua \\
\hline & & Mean \pm SD & $N$. & $N$. & $N$. & $N$. & $N$. & $N$. & $N$. & $N$. \\
\hline all & 8497 & $21.1 \pm 2.0$ & 4385 & 252 & 3860 & 7939 & 162 & 396 & 7190 & 2777 \\
males & 2990 & $21.3 \pm 2.0$ & 1929 & 133 & 928 & 2747 & 68 & 175 & 2531 & 969 \\
females & 5507 & $21.0 \pm 1.9$ & 2456 & 119 & 2932 & 5192 & 94 & 221 & 4659 & 1808 \\
\hline
\end{tabular}






Figure 1. Criteria adopted to enroll students in the study. Only vaccinated students, born in Italy, who presented a vaccine certificate released by the Public Health Office and with quantitative measurement of measles antibodies were enrolled.

\subsection{Measurement of Measles Antibodies}

The measles IgG antibodies were measured by means of commercial enzyme-linked immunosorbent assay (EIA) Enzygnost (Dade Behring, Marburg, Germany). Antibody levels of measles were reported as positive (higher than $350 \mathrm{IU} / \mathrm{mL}$ ), negative (lower than $150 \mathrm{IU} / \mathrm{mL}$ ), or equivocal (150-350 IU/mL). Equivocal results had been statistically processed as negative according to $\mathrm{CDC}$ recommendations [16].

\subsection{Statistics}

Chi-square $\left(\chi^{2}\right)$ test 2 by 2 (Yates correction) was used to compare the prevalence of antibody positivity. Comparison between means was done with unpaired t-test, assuming unequal variances. We adjusted the results for multiple testing by considering the Bonferroni correction in which the $p$-values are multiplied by the number of comparisons. Multiple linear regression based on the logarithms of antibody titer (being asymmetric its distribution) was used to analyze the variables influencing antibodies titer (dependent variable), and the following outcomes were considered as independent variables: (1) sex, (2) age at first dose of vaccine, (3) time since the dose (or the second dose) of vaccine, and (4) typology of vaccine categorized as 1 (measles alone), 2 (MMR), 3 (measles alone plus measles alone), 4 (measles alone plus MMR) and 5 (two doses of MMR). Typology 1 is the reference type. Linear regression coefficient $r$ (Pearson product-moment correlation coefficient) was used (if appropriate) to relate single independent variables with antibody titer. Furthermore, four years of birth groups were assumed as previously [14]: born in 1980-1985, 1986-1990, 1991-1995, and after 1995. Other statistical analyses are descriptive. Significance is stated by $p<0.05$. Statsdirect 2.7 .7 version (Statsdirect Ltd., Birkenhead, Merseyside, UK) has been used for statistical analyses. 


\section{Results}

On the enrolled population attending medical school courses and born since 1980, $94.1 \%$ were vaccinated toward measles ( $22.4 \%$ one dose, $77.6 \%$ two doses), including significantly $(p=0.0041)$ more females $(94.7 \%)$ than males $(93.1 \%)$ (data not shown).

The vaccination schedule (Figure 2 ) is very different depending on the year of birth. One dose of vaccine was prevalently adopted before 1990, with a prevalence of measles alone before 1985. Children born after 1995 were covered by two doses of MMR vaccine.

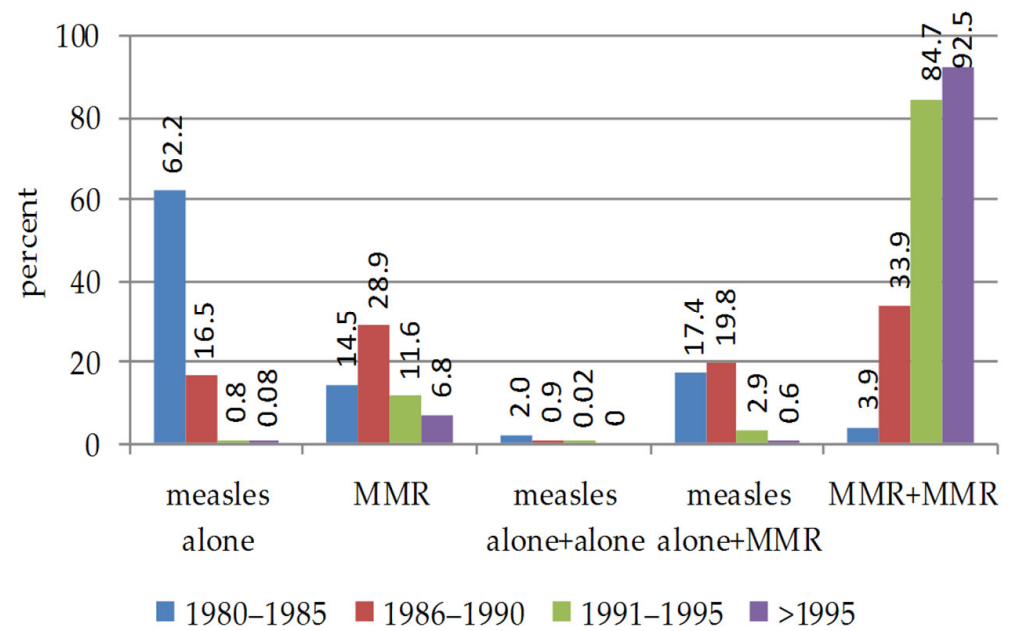

Figure 2. Percentage of vaccinated students according to adopted vaccination schedule. They are subdivided according to year of birth group. The Public Office certified that the measles vaccine was administered according to one dose schedule, alone or MMR, or two doses (two doses of measles alone, a dose of measles alone plus MMR, or two doses of MMR).

By the vaccination certificate (data not shown), students vaccinated once received the vaccine dose at a significantly $(p<0.0001)$ later age as compared to those vaccinated twice $(3.9 \pm 4.2$ and $1.9 \pm 1.8$ years of age, respectively), especially if vaccinated with the MMR vaccine. The timing and type of vaccination is dependent on year of birth.

The most relevant result is that one dose induces a significantly $(p<0.0001)$ higher prevalence of positives antibodies and higher antibody titer than two doses, despite the longer (about double) time since the last dose; furthermore, the measles vaccine alone is most effective, and this is confirmed by the double use of measles alone that induces a similar high percentage of positives (96.7\% vs. $96.6 \%$ ) and antibody titer (Table 2$)$.

Table 2. Percentage of positive students and antibody titer according to vaccination schedule.

\begin{tabular}{|c|c|c|c|c|c|c|}
\hline \multirow{2}{*}{ Vaccination Schedule } & \multirow{2}{*}{$N$} & \multirow{2}{*}{ Positives } & \multirow{2}{*}{$\%$} & \multirow{2}{*}{ Significance } & Titer IU/mL & \multirow{2}{*}{ Significance } \\
\hline & & & & & Mean $\pm S D$ & \\
\hline all one dose & 1902 & 1663 & 87.4 & a & $1730.2 \pm 1873.3$ & aa \\
\hline measles alone & 702 & 678 & 96.6 & $b, c, d$ & $1824.2 \pm 1673.1$ & dd \\
\hline MMR & 1200 & 985 & 82.1 & $b, e, f$ & $1675.1 \pm 1979.7$ & ee,ff \\
\hline all two doses & 6595 & 5144 & 78.0 & a & $1335.5 \pm 1686.3$ & aa \\
\hline measles alone + measles alone & 30 & 29 & 96.7 & & $1875.0 \pm 1342.4$ & \\
\hline measles alone $+\mathrm{MMR}$ & 581 & 535 & 92.1 & $c, e, g$ & $1668.0 \pm 1697.9$ & ee,gg \\
\hline $\mathrm{MMR}+\mathrm{MMR}$ & 5984 & 4580 & 76.5 & $\mathrm{~d}$ & $1300.5 \pm 1682.9$ & dd \\
\hline
\end{tabular}

Legend: meaning of superscript letters: ${ }^{a}$ percentage of positives $(p<0.0001)$ and aa titer $(p<0.0001)$ after one dose vs. two doses; ${ }^{\mathrm{b}}$ percentage of positives $(p<0.0001)$ after one dose of measles alone vs. one dose of MMR; ${ }^{\mathrm{c}}$ percentage of positives $(p=0.0065)$ after one dose of measles alone vs. two doses of measles alone plus MMR; ${ }^{d}$ percentage of positives $(p<0.0001)$ and ${ }^{d d}$ titer $(p<0.0001)$ after one dose of measles alone vs. two doses of MMR; ${ }^{\mathrm{e}}$ percentage of positives $(p<0.0001)$ and ${ }^{\mathrm{ee}}$ titer $(p<0.0001)$ after two doses of measles alone plus MMR vs. one dose of MMR; ${ }^{\mathrm{f}}$ percentage of positives $(p=0.0003)$ and ${ }^{\mathrm{ff}}$ titer $(p<0.0001)$ after one dose of MMR vs. two doses of MMR; $\mathrm{g}$ percentage of positives $(p<0.0001)$ and gg titre $(p<0.0001)$ after two doses of measles alone plus MMR vs. two doses of MMR. 
Overall, females are more responsive than males to measles vaccine (Table 3 ) after one $(p=0.0004$ positives and $p=0.0010$ titer) or two doses $(p<0.0001$ positives and $p=0.0110$ titre), but only when MMR (once or twice) is administered.

Table 3. Percentage of positive students and antibody titer according to sex and vaccination schedule.

\begin{tabular}{cccccccc}
\hline \multirow{2}{*}{ Doses } & Vaccination Schedule & Sex & N. & Positives & \% & Significance & Titer IU/mL \\
& & & & & & Mean \pm SD \\
\hline 1 & all & males & 721 & 602 & 83.5 & & $1528.3 \pm 1743.4$ \\
1 & all & females & 1181 & 1061 & 89.8 & $\mathrm{a}$ & $1853.4 \pm 1938.8$ \\
1 & measles alone & males & 242 & 234 & 96.7 & & $1789.8 \pm 1806.1$ \\
1 & measles alone & females & 460 & 444 & 96.5 & & $1842.4 \pm 1600.5$ \\
1 & MMR & males & 479 & 368 & 76.8 & & $1396.1 \pm 1697.5$ \\
1 & MMR & females & 721 & 617 & 85.6 & $\mathrm{~b}$ & $1860.5 \pm 2127.7$ \\
2 & all & males & 2269 & 1689 & 74.4 & & $1247.5 \pm 1629.6$ \\
2 & all & females & 4326 & 3455 & 79.9 & $\mathrm{c}$ & $1381.6 \pm 1713.6$ \\
2 & measles alone+alone & males & 10 & 10 & 100.0 & & $1906.0 \pm 1349.2$ \\
2 & measles alone+alone & females & 20 & 19 & 95.0 & & $1859.5 \pm 1373.9$ \\
2 & measles alone+MMR & males & 147 & 136 & 92.5 & & $1668.4 \pm 1461.1$ \\
2 & measles alone+MMR & females & 434 & 399 & 91.9 & & $1667.9 \pm 1772.5$ \\
2 & MMR+MMR & males & 2112 & 1543 & 73.1 & \multirow{2}{*}{ a } & $1215.1 \pm 1637.8$ \\
2 & MMR+MMR & females & 3872 & 3037 & 78.4 & $\mathrm{~d}$ & $1347.0 \pm 1705.5$ \\
\hline
\end{tabular}

Legend: meaning of superscript letters: ${ }^{\text {a }}$ percentage of positives $(p=0.0004)$ and ${ }^{\text {aa }}$ titer $(p=0.0010)$ after one dose, females vs. males; ${ }^{\mathrm{b}}$ percentage of positives $(p=0.0067)$ and ${ }^{\mathrm{bb}}$ titer $(p=0.0137)$ after one dose of MMR, females vs. males; ${ }^{\mathrm{c}}$ percentage of positives $(p<0.0001)$ and ${ }^{c c}$ titer $(p=0.0110)$ after two doses, females vs. males; ${ }^{\mathrm{d}}$ percentage of positives $(p=0.0001)$ after two doses of MMR, females vs. males.

Multiple linear regression analysis highlights that all independent variables influence antibody titer, and it confirms that vaccine typology 1 (one dose of measles alone) is the most effective, followed by typology 3 and 4, while typology 2 (one dose of MMR) and 5 (two doses of MMR) appear to be the least effective (Table 4). Sex significantly $(p<0.0001)$ influences antibody titer but only when MMR was used. In addition, the more delayed the first dose, the better the antibody response, as also demonstrated by the linear correlation between the log of the antibody titer and the log of age at the first dose $(r=0.154, p<0.0001)$. Finally, the time between vaccination and antibody titer analysis on multivariate analysis seems to have some influence, which is not confirmed by the linear regression between the two variables $(r=0.0058, p=0.5924)$.

Table 4. Multiple linear regression among the logarithmic transformation of antibody titer of measles in vaccinated students and the independent variables sex, age of vaccination (or first dose of vaccine), time between vaccination, and antibody measurement and typology of vaccination (see legend). Statistically significant results are in bold.

\begin{tabular}{ccccc}
\hline & $\mathbf{b}$ & $\mathrm{SE}$ & $\mathbf{t}$ & $p$ \\
\hline Intercept & 3.194 & 0.044 & 71.887 & $<0.0001$ \\
sex & 0.060 & 0.101 & 5.985 & $<0.0001$ \\
typology 1 & 0.000 & & & \\
typology 2 & -0.189 & 0.022 & -8.563 & $<0.0001$ \\
typology 3 & -0.008 & 0.084 & -0.100 & 0.92 \\
typology 4 & -0.147 & 0.031 & -4.678 & $<0.0001$ \\
typology 5 & -0.312 & 0.026 & -11.714 & $<0.0001$ \\
age 1st dose & 0.000 & 0.000 & 6.774 & $<0.0001$ \\
time & -0.000 & 0.000 & -4.584 & $<0.0001$
\end{tabular}

Legend: typology 1 signifies one dose with measles alone (reference typology), typology 2 signifies one dose of MMR, typology 3 signifies two doses of measles alone, typology 4 signifies one dose of measles alone plus one dose of MMR, typology 5 signifies two doses of MMR. In the header: $b=$ slope, $S E=$ standard error of $b, t=t$-test; that is, the relationship between $b$ and SE. 
Finally, if stratified by year of birth groups, those born between 1980 and 1990 have a significantly $(p<0.0001)$ higher response in terms of positive antibodies and antibody titer than younger groups after one and two doses (Table 5). In addition, sex differences were statistically significant in a randomized manner between the groups.

Table 5. Percentage of positive antibodies and antibody titer according to doses of vaccine and sex. The $p$ values refer to the statistical comparison between males and females.

\begin{tabular}{|c|c|c|c|c|c|c|c|}
\hline $\begin{array}{c}\text { Year of Birth } \\
\text { One Dose }\end{array}$ & & $N$ & Positives & $\%$ & $p$ & $\begin{array}{l}\text { Titer IU/mL } \\
\text { Mean } \pm \text { SD }\end{array}$ & $p$ \\
\hline \multirow[t]{3}{*}{ 1980-1985 } & all & 454 & 448 & 98.7 & & $1997.6 \pm 1818.7$ & \\
\hline & males & 157 & 153 & 97.5 & & $1779.4 \pm 1630.6$ & \\
\hline & females & 297 & 295 & 99.3 & 0.2182 & $2113.0 \pm 1903.2$ & 0.0514 \\
\hline \multirow[t]{3}{*}{ 1986-1990 } & all & 832 & 798 & 95.9 & & $1822.1 \pm 1756.2$ & \\
\hline & males & 293 & 275 & 93.9 & & $1798.0 \pm 1923.9$ & \\
\hline & females & 539 & 523 & 97.0 & 0.0428 & $1835.3 \pm 1659.7$ & 0.7795 \\
\hline \multirow[t]{3}{*}{ 1991-1995 } & all & 441 & 286 & 64.9 & & $1477.1 \pm 2167.6$ & \\
\hline & males & 189 & 110 & 58.2 & & $1097.9 \pm 1603.9$ & \\
\hline & females & 252 & 176 & 69.8 & 0.0150 & $1761.5 \pm 2473.9$ & 0.0007 \\
\hline \multirow[t]{3}{*}{ after 1995} & all & 175 & 131 & 74.9 & & $1236.6 \pm 1576.0$ & \\
\hline & males & 82 & 64 & 78.0 & & $1075.6 \pm 1248.0$ & \\
\hline & females & 93 & 67 & 72.0 & 0.4597 & $1378.5 \pm 1811.9$ & 0.1955 \\
\hline $\begin{array}{c}\text { Year of Birth } \\
\text { Two Doses }\end{array}$ & & $N$ & Positives & $\%$ & $p$ & $\begin{array}{c}\text { titer } \mathrm{IU} / \mathrm{mL} \\
\text { Mean } \pm \mathrm{SD}\end{array}$ & $p$ \\
\hline \multirow[t]{3}{*}{ 1980-1985 } & all & 138 & 135 & 97.8 & & $1733.2 \pm 1465.6$ & \\
\hline & males & 43 & 40 & 93.0 & & $1630.2 \pm 1147.9$ & \\
\hline & females & 95 & 95 & 100.0 & 0.0485 & $1779.8 \pm 1592.1$ & 0.5334 \\
\hline \multirow[t]{3}{*}{ 1986-1990 } & all & 1000 & 960 & 96.0 & & $1717.2 \pm 1713.4$ & \\
\hline & males & 317 & 299 & 94.3 & & $1564.4 \pm 1477.7$ & \\
\hline & females & 683 & 661 & 96.8 & 0.0946 & $1788.1 \pm 1809.1$ & 0.0388 \\
\hline \multirow[t]{3}{*}{ 1991-1995 } & all & 3103 & 2191 & 70.6 & & $1377.4 \pm 1855.5$ & \\
\hline & males & 1114 & 743 & 66.7 & & $1325.8 \pm 1842.2$ & \\
\hline & females & 1989 & 1448 & 72.8 & 0.0004 & $1406.3 \pm 1862.7$ & 0.2454 \\
\hline \multirow[t]{3}{*}{ after 1995} & all & 2354 & 1858 & 78.9 & & $1094.7 \pm 1388.2$ & \\
\hline & males & 795 & 607 & 76.4 & & $990.7 \pm 1329.4$ & \\
\hline & females & 1559 & 1251 & 80.2 & 0.0327 & $1147.7 \pm 1414.7$ & 0.0081 \\
\hline
\end{tabular}

The students never vaccinated against measles (531 individuals, data not shown) were excluded from the casuistry according to enrollment criteria, but they have a certain relevance. A significantly $(p<0.0001)$ high prevalence of positive antibodies $(97.5 \%$ and $87.4 \%$, respectively) and antibody titer $(6263.6 \pm 4340.9$ and $6375.0 \pm 4600.2 \mathrm{IU} / \mathrm{mL}$, respectively) was observed in students born in 1980-1985 and 1986-1990 compared to those born in 1991-1995 (prevalence 32.5\%, antibody titer 2291.1 $\pm 3882.1 \mathrm{IU} / \mathrm{mL}$ ) and after 1995 (prevalence $14.3 \%$, titer $386.7 \pm 1012.6 \mathrm{IU} / \mathrm{mL}$ ).

\section{Discussion}

Measles is probably the most contagious infectious disease for humans [17]. In Italy, the implementation of vaccination is the reason for the decline of measles incidence from $150 / 100,000$ cases in the sixties to 5/100,000 in 2001 and to $0.3 / 100,000$ in 2020. The relationship between measles vaccination coverage and hospitalization rate is inversely related [18]. However, vaccine implementation and the prevalence of positive antibodies are still insufficient to eradicate measles [19].

The effectiveness of vaccination against measles was evaluated in a large population of students attending courses of the School of Medicine of Padua University and subjected to health surveillance according to the law. The aim of the study was to ascertain the prevalence of positive antibody and the antibody titer according to vaccination schedule (one or two doses), vaccine type (vaccine containing measles attenuated virus alone or 
combined as MMR), and sex also. The first strength is the number of the enrolled students, who were all born in Italy and therefore subjected to the same vaccination schedule; the second strength is that all recruited students had a vaccination certificate released by the Public Health Office. Given these solid bases (population size and certainty about vaccination), the results obtained can establish a definitive point on the seroprevalence of antibodies in response to vaccination against measles. Reasons for weakness could be seen in the clear numerical difference between males and females (difference due to the predominant female presence in the degree courses of the health professions) and that the age of first administration is not the same for everyone but depends on the years in which were born. A further limitation could be the absence of some information on attitudes practices toward measles vaccination among the students, but this is a retrospective study based on data collected during health surveillance.

Three are the main results in this study: (1) to our knowledge, for the first time it is proved that measles vaccine alone appears somewhat more effective than MMR combination, and that one dose apparently induces a higher percentage of seropositivity and a higher antibody titer than two doses (unless one or both doses are measles alone); (2) there is high vaccine coverage in the younger generations; (3) vaccine, either one or two doses, induces a significantly higher prevalence of positive antibodies and higher antibody titer in females than in males.

The first evidence is not easily understood. A possible explanation has been recently suggested on a "negative" influence of the Rubini strain in MMR combination used for mumps between 1990 and 1995 [14], but at the moment, it remains unresolved. Nevertheless, the recent WHO position paper on measles vaccine [20] claims that "although vaccine-induced antibody concentrations decline over time and may become undetectable, immunological memory persists and, following exposure to measles virus, most people who have been vaccinated produce a protective immune response". Although serum IgG measles titer declines during time, this does not happen for measles-specific neutralizing antibody titer [21], and two doses of measles vaccine results in high seropositivity, vaccine effectiveness, and T-cell response [22].

The second evidence highlights the significant effort made by health authorities to involve families in the vaccination program for the purpose to eradicate transmittable diseases such as measles, mumps, and rubella by achieving herd immunity. Regarding measles, the objective is complicated by the fact that herd immunity can only be achieved with a vaccination coverage over $95 \%$, practically vaccinating all newborns [23].

The third evidence is that females have a significant higher percentage of positive response and higher antibody titer after vaccination than in males. Sex could be a variable in response to measles vaccination and disagree with other research [24] that do not support the fact that sex influences measles humoral and cellular immunity.

Sex differences in response to vaccine were recognized previously [25-27]; females develop a higher titer of neutralizing antibodies [28]. Inasmuch, if innate immunity is similar in both sexes, adaptive immunity is more pronounced in females [25]. Furthermore, differences in Toll-like receptor pathway and type I interferon induction may explain these differences [29], being several immune-related genes located on the $X$ chromosome and play a pivotal role in immune competence [30]. Therefore, it is plausible that there are different immune responses if the vaccination is administered at different ages; measles vaccination is administered during the second year of life when adaptive immunity should be just developed. On the other hand, these differences are significant only if MMR (once or twice, indifferently) is adopted but not if measles vaccine alone was used.

The significant reduction in the circulation of the wild virus, as demonstrated by the low prevalence of positive antibodies in the unvaccinated younger student population, certainly reduces the possibility of natural boosters in vaccinated subjects resulting in a waning of circulating antibodies (but of immune memory also?) and a possible resurgence of measles outbreaks [31]. In addition, a booster dose is suggested in unprotected subjects after two doses of the vaccine, and a high seroconversion was observed [32]. 
The measles epidemic of 2017 in Italy prompted the government to enact a law to make 10 vaccines, including measles, mandatory from 0 to 16 years [5]. The mandatory effect has resulted in a significant increase in vaccination coverage $[33,34]$, but this is not always understood and shared. An experiment of some interest began in the Veneto Region (Italy) in 2007 with the suspension of the vaccination obligation against poliomyelitis, diphtheria, tetanus, and hepatitis B, simultaneously investing in a health education campaign [35]. In any case, the study population, even if for the most part born and resident in Veneto, is not among the cohorts involved in the project.

Finally, the phenomenon of vaccine hesitancy is the cause of low vaccination coverage even among HCWs [36,37]. As previously reported [14], this phenomenon will certainly be much less evident in the near future given that our series shows a high vaccination coverage in what will be future HCWs.

\section{Conclusions}

Two are the main conclusions of this study: (i) females are more responsive to measles vaccination than males but only when MMR combined vaccine is used, and (ii) there is a better positive response and higher antibody titer if measles is administered alone (one or two dose), or measles alone plus MMR. Both evidences are intriguing, but the second is not easily to explain and remains an objective for further studies.

Despite the unavailability of the measles vaccine alone, it could be apposite that the pharmaceutical companies prepare and make available single doses to be used, in case as a booster, in HCWs, especially if the positivity against mumps and rubella is confirmed by the laboratory. Therefore, in this case, it would be interesting to study, in a time of low virus circulation, the differences in the antibody response between the measles vaccine alone and that in the MMR formulation.

The medical students (medicine, dentistry, and healthcare professions) will be future HCWs; then, particular attention must be given to the fact that they may have very close contact with patients affected by infectious diseases during their training and profession, mainly when transmitted by air.

Author Contributions: Conceptualization, A.T., A.N., S.M., P.M., A.M., and M.L.S.; methodology, B.S.; A.T.; validation, A.T., A.N., S.M., P.M., and M.L.S.; formal analysis, A.T.; data curation, A.T., A.N., and M.L.S.; writing-original draft preparation, A.T.; writing-review and editing, A.T., A.M., and M.L.S. supervision, A.T.; All authors have read and agreed to the published version of the manuscript.

Funding: This research received no external funding.

Institutional Review Board Statement: This is an observational study in which we analyzed data derived from a mandatory health surveillance activity on workers exposed to biological risk as regulated by the Italian legislative decree $81 / 2008$; consequently, the evaluation by an ethic committee was not necessary.

Informed Consent Statement: Students subscribed an information note on the processing of personal and sensitive in which they also expressed consent to the possibility that data collected are processed anonymously for epidemiological investigations and/or for scientific research purposes.

Data Availability Statement: Raw data are available on request from the corresponding author.

Conflicts of Interest: The authors declare no conflict of interest.

\section{References}

1. Ministero della Sanità. Circolare $n^{\circ}$ 41. Profilassi del Morbillo (Circular 41. Measles Prophylaxis); Ministry of Health: Rome, Italy, 25 June 1979.

2. Ministero della Salute. Circolare $n^{\circ}$ 12. Controllo ed Eliminazione di Morbillo, Parotite e Rosolia per Mezzo della Vaccinazione (Circular 12. Control and Elimination of Measles, Mumps and Rubella by Means of Vaccination); Ministry of Health: Rome, Italy, 13 July 1999.

3. Decreto Presidente Consiglio dei Ministri. Piano Nazionale per L'eliminazione del Morbillo e della Rosolia Congenita (Presidential Decree of the Council of Ministers. National Plan for the Elimination of Measles and Congenital Rubella); Presidency of the Council: Rome, Italy, 29 November 2001. 
4. World Health Organization. Global Measles and Rubella Strategic Plan 2012-2020; World Health Organization: Geneva, Switzerland, 2012.

5. Decreto Legge n. 73. Disposizioni Urgenti in Tema di Prevenzione Vaccinale (Law Decree N. 73. Urgent Provisions on Vaccine Prevention); N. 130; Gazzetta Ufficiale: Rome, Italy, 7 June 2017.

6. Piano Nazionale Prevenzione Vaccinale 2017-2019 (National Vaccination Prevention Plan 2017-2019); Ministero della Salute: Rome, Italy, 17 January 2017.

7. Position Paper: La Carta di Pisa delle vaccinazioni negli operatori sanitari (The Pisas' Paper of Vaccinations in Healthcare Professionals). GlmPIOS 2017, 7, 155-157.

8. Anderson, R.M.; May, R.M. Immunisation and herd immunity. Lancet 1990, 335, 641-645. [CrossRef]

9. Watson, J.C.; Pearson, J.A.; Markowitz, L.E.; Baughman, A.L.; Erdman, D.D.; Bellini, W.J.; Baron, R.C.; Fleming, D.W. Evaluation of measles revaccination among schoolentry-aged children. Pediatrics 1996, 97, 613-618.

10. Davidkin, I.; Jokinen, S.; Broman, M.; Leinikki, P.; Peltola, H. Persistence of measles, mumps, and rubella antibodies in an MMR-vaccinated cohort: A 20-years follow-up. J. Infect. Dis. 2008, 197, 950-956. [CrossRef] [PubMed]

11. Trevisan, A.; Morandin, M.; Frasson, C.; Paruzzolo, P.; Davanzo, E.; Di Marco, L.; Fabrello, A.; Borella-Venturini, M. Prevalence of childhood exanthematic disease antibodies in paramedical students: Need of vaccination. Vaccine 2006, 24, 171-176. [CrossRef] [PubMed]

12. Trevisan, A.; Frasson, C.; Morandin, M.; Beggio, M.; Bruno, A.; Davanzo, E.; Di Marco, L.; Simioni, L.; Amato, G. Immunity against infectious diseases: Predictive value of self-reported history of vaccination and disease. Infect. Control Hosp. Epidemiol. 2007, 28, 564-569. [CrossRef]

13. Trevisan, A.; Morandin, M.; Frasson, C.; Pantaleoni, A.; Donazzan, A.; Ballarin, D.; Nicolli, A.; Bartolucci, G.B.; Chiara, F. Prevalence of measles virus-specific IgG antibodies according to vaccination schedule in medical students of Padua University. Future Virol. 2015, 10, 817-826. [CrossRef]

14. Trevisan, A.; Bertoncello, C.; Artuso, E.; Frasson, C.; Lago, L.; De Nuzzo, D.; Nicolli, A.; Maso, S. Will we have a cohort of healthcare workers full vaccinated against measles, mumps, and rubella? Vaccines 2020, 8, 104. [CrossRef] [PubMed]

15. Decreto Legislativo n. 81. Tutela della Salute e della Sicurezza nei Luoghi di Lavoro (Protection of Health and Safety in the Workplace); N. 101; Gazzetta Ufficiale: Rome, Italy, 2008.

16. Centers for Disease Control and Prevention. Prevention of varicella. Update recommendations of the Advisory Committee on Immunization Practices (ACIP). MMWR 1999, 48, 1-5.

17. Katz, S.L.; Enders, J.F.; Holloway, A. Use of Edmonston attenuated measles strain. A summary of three years' experience. Am. J. Dis. Child. 1962, 103, 340-344. [CrossRef]

18. Degli Atti, M.L.C.; Rota, M.C.; Bella, A.; Salmaso, S.; ICONA Study Group. Do changes in policy affect vaccine coverage levels? Results of a national study to evaluate childhood vaccination coverage and reasons for missed vaccination in Italy. Vaccine 2004, 22, 4351-4357. [CrossRef] [PubMed]

19. Rota, M.C.; Massari, M.; Gabutti, G.; Guido, M.; De Donno, A.; Ciofi degli Atti, M.L. Measles serological survey in the Italian population: Interpretation of results using mixture model. Vaccine 2008, 26, 4403-4409. [CrossRef] [PubMed]

20. Measles vaccines: WHO position paper-April 2017. Wkly Epidemiol. Rec. 2017, 92, 205-227. Available online: https://www.who. int/wer/2017/wer9217/en/ (accessed on 28 April 2017).

21. Kennedy, R.B.; Ovsyannikova, I.G.; Thomas, A.; Larrabee, B.R.; Rubin, S.; Poland, G.A. Differential durability of immune responses to measles and mumps following MMR vaccination. Vaccine 2019, 37, 1775-1784. [CrossRef] [PubMed]

22. Nic Lochlainn, L.M.; de Gier, B.; van der Maas, N.; van Binnendijk, R.; Strebel, P.M.; Goodman, T.; de Melker, H.E.; Moss, W.J.; Hahné, S.J.M. Effect of measles vaccination in infants younger than 9 months on the immune response to subsequent measles vaccine doses: A systematic review and meta-analysis. Lancet Infect. Dis. 2019, 19, 1246-1254. [CrossRef]

23. Bester, J.C. Measles vaccination is best for children: The argument for relying on herd immunity fails. J. Bioeth. Inq. 2017, 14, 375-378. [CrossRef]

24. Voigt, E.A.; Ovsyannikova, I.G.; Haralambieva, I.H.; Kennedy, R.B.; Larrabee, B.R.; Schaid, D.J.; Poland, G.A. Genetically defined race, but not sex, is associated with higher humoral and cellular immune responses to measles vaccination. Vaccine 2016, 34, 4913-4919. [CrossRef]

25. Klein, S.L.; Jedlicka, A.; Pekosz, A. The Xs and Y of immune responses to viral vaccines. Lancet Infect. Dis. 2010, 10, 338-349. [CrossRef]

26. Cook, I.F. Sexual dimorphism of humoral immunity with human vaccines. Vaccine 2008, 26, 3551-3555. [CrossRef]

27. Kennedy, R.B.; Ovsyannikova, I.G.; Pankratz, V.S.; Vierkant, R.A.; Jacobson, R.M.; Ryan, M.A.; Poland, G.A. Gender effects on humoral immune responses to smallpox vaccine. Vaccine 2009, 27, 3319-3323. [CrossRef]

28. Furman, D.; Hejblum, B.P.; Simon, N.; Jojic, V.; Dekker, C.L.; Thiébaut, R.; Tibshirani, R.J.; Davis, M.M. Systems analysis of sex differences reveals an immunosuppressive role for testosterone in the response to influenza vaccination. Proc. Natl. Acad. Sci. USA 2014, 11, 869-874. [CrossRef]

29. Hannah, M.F.; Bajic, V.B.; Klein, S.L. Sex differences in the recognition of and innate antiviral responses to Seoul virus in Norway rats. Brain. Behav. Immun. 2008, 22, 503-516. [CrossRef]

30. Abramowitz, L.K.; Olivier-Van Stichelen, S.; Hanover, J.A. Chromosome imbalance as a driver of sex disparity in disease. J. Genom. 2014, 2, 77-88. [CrossRef] [PubMed] 
31. Bianchi, F.P.; Mascipinto, S.; Stefanizzi, P.; De Nitto, S.; Germinario, C.; Tafuri, S. Long-term immunogenicity after measles vaccine vs. wild infection: An Italian retrospective cohort study. Hum. Vaccin. Immunother. 2021, 27, 1-7. [CrossRef] [PubMed]

32. Bianchi, F.P.; Stefanizzi, P.; De Nitto, S.; Larocca, A.M.V.; Germinario, C.; Tafuri, S. Long-term Immunogenicity of Measles Vaccine: An Italian Retrospective Cohort Study. J. Infect. Dis. 2020, 221, 721-728. [CrossRef]

33. Signorelli, C.; Iannazzo, S.; Odone, A. The imperative of vaccination put into practice. Lancet Infect. Dis. 2018, 18, 26-27. [CrossRef]

34. Burioni, R.; Odone, A.; Signorelli, C. Lessons from Italy's policy shift on immunization. Nature 2018, 555, 30. [CrossRef] [PubMed]

35. Valsecchi, M.; Cinquetti, S.; Ferro, A. Vaccination coverage in Veneto Region (Northern Italy): Reading data correctly. Epidemiol. Prev. 2018, 42, 196-197. [PubMed]

36. Di Martino, G.; Di Giovanni, P.; Di Girolamo, A.; Scampoli, P.; Cedrone, F.; D’Addezio, M.; Meo, F.; Romano, F.; Di Sciascio, M.B.; Staniscia, T. Knowledge and Attitude towards Vaccination among Healthcare Workers: A Multicenter Cross-Sectional Study in a Southern Italian Region. Vaccines 2020, 8, 248. [CrossRef] [PubMed]

37. Genovese, C.; Picerno, I.A.M.; Trimarchi, G.; Cannavò, G.; Egitto, G.; Cosenza, B.; Merlina, V.; Icardi, G.; Panatto, D.; Amicizia, D.; et al. Vaccination coverage in healthcare workers: A multicenter cross-sectional study in Italy. J. Prev. Med. Hyg. 2019, 60, E12-E17. [PubMed] 